\title{
Parenteral nutrition therapy for neonates: Experience in a tertiary care centre in Sri Lanka
}

\author{
*C M Wickramatilake ${ }^{1}$, K Withanaarachchi $^{2}$, R A Dharmadasa ${ }^{3}$, M T J Amaraweera ${ }^{3}$, S R Dissanayake ${ }^{3}$
}

Sri Lanka Journal of Child Health, 2018; 47(1): 16-20

\begin{abstract}
Background: There is scarce literature about the practice of parenteral nutrition $(\mathrm{PN})$ in neonates in Sri Lanka.
\end{abstract}

Objectives: To describe the characteristics of neonates receiving $\mathrm{PN}$, the current practice of $\mathrm{PN}$ and the complications developing in neonates receiving $\mathrm{PN}$ in Sri Lanka.

Method: A descriptive cross-sectional study was conducted on babies receiving $\mathrm{PN}$ after admission to the Special Care Baby Unit of a Tertiary Care Centre in Sri Lanka during 2014. Data was gathered from mothers, medical records and by clinical examination of the babies.

Results: Fifty six neonates were on PN during 2014. Twenty (36\%) were on PN for 4 days. All babies were fed on breast milk as the trophic feeds except one who was given formula milk. Initiation of trophic feeds was early (median day 2). Fifty one $(91 \%)$ were started on trophic feeds by day 3 with $14(25 \%)$ on day 1 . Twenty six (46\%) developed complications consisting of septicaemia (5), hypoglycaemia (9), hyperglycaemia (2), hypernatraemia (23), catheter site related complications (4) and thrombocytopenia (7).

Conclusions: The median duration of PN was 4 days. Trophic feeds with expressed breast milk were started in $91 \%$ by day three. Forty six percent of babies on PN developed complications.

\footnotetext{
${ }^{1}$ Senior Lecturer, Department of Biochemistry, Faculty of Medicine, University of Ruhuna, Sri Lanka, ${ }^{2}$ Neonatal Intensivist, Neonatal Intensive Care Unit, Teaching Hospital, Karapitiya, Galle, Sri Lanka. ${ }^{3}$ Medical officer, Special Care Baby Unit, Teaching Hospital Mahamodara, Galle *Correspondence: chandimadhu@live.com
}

(Received on 30 March 2017: Accepted after revision on 19 May 2017)

The authors declare that there are no conflicts of interest

Personal funding was used for the project.

Open Access Article published under the Creative

Commons Attribution CC-BY (CC) (P)
DOI: http://dx.doi.org/10.4038/sljch.v47i1.8424

(Keywords: Complication, neonate, parenteral nutrition)

\section{Introduction}

First few days of life are a transient period where the newborn adapts to postnatal life where there is a high risk of growth restriction, if adequate nutrients are not received by the baby. The adverse effects of poor nutrition are more pronounced among the premature and low birth weight babies $^{1,2}$. Therefore, adequate nutrients via parenteral nutrition $(\mathrm{PN})$ in babies who are unable to be fed on enteral route have a positive impact on the growth and the reduction of mortality and morbidity of these babies $^{3}$. However, PN is associated with the risk of contamination and sepsis, cholestasis and metabolic derangements such as hyperlipidaemia, hypernatraemia and hyperglycaemia in neonates ${ }^{2,4}$. In the Sri Lankan set up, research evidence on $\mathrm{PN}$ in neonatal healthcare is scarce and needs to be studied.

\section{Objectives}

To describe the characteristics of neonates receiving $\mathrm{PN}$, the current practice of $\mathrm{PN}$ and the complications developing in neonates receiving PN at the Special Care Baby Unit (SCBU) of a Tertiary Care Centre in Sri Lanka.

\section{Method}

A prospective cross-sectional study was conducted in the SCBU of a Tertiary Care Centre in Sri Lanka among babies receiving PN in 2014. Babies with cholestasis due to anatomical obstruction of the hepatobiliary tract, metabolic disease or inborn errors of metabolism and those whose mothers refused were excluded. After obtaining informed written consent from the mother, data was gathered using an interviewer-administered questionnaire from mothers and from the bed head ticket, investigation reports, and monitoring charts and by the examination of "babies. Ethical clearance was obtained from the local ethics review committee. Data was presented as percentages and frequencies.

\section{Results}

Out of 766 total admissions to SCBU, 56 babies received $\mathrm{PN}$ in 2014. The descriptive data of the newborns are shown in Table 1. 
Table 1: Descriptive data of the babies $(n=56)$

\begin{tabular}{|l|c|}
\hline \multicolumn{1}{|c|}{ Character } & Result \\
\hline Median duration of stay at Special Care Baby Unit in days = No. (range) & $22(05-56)$ \\
\hline Median duration of parenteral nutrition in days = No. (range) & $04(02-09)$ \\
\hline Gestational age at birth & $09(16.1)$ \\
Less than 28 weeks - No. (\%) & $20(35.7)$ \\
28 to 31 weeks - No. (\%) & $25(44.6)$ \\
32 to 37 weeks - No. (\%) & $02(03.6)$ \\
More than 37 weeks - No. (\%) & $17(30.3)$ \\
\hline Birth weight & $33(58.9)$ \\
Less than 1000g - No. (\%) & $06(10.7)$ \\
1000-1499g - No. (\%) & $39(69.6)$ \\
1500-2499g - No. (\%) & $17(30.4)$ \\
\hline Route of parenteral nutrition & \\
Central route (umbilical catheter) - No. (\%) & $54(96.4)$ \\
Peripheral route - No. (\%) & $02(03.6)$ \\
\hline Indication for parenteral nutrition & $08(14.5)$ \\
Prematurity and low birth weight - No. (\%) & \\
Respiratory distress - No. (\%) & $05(08.9)$ \\
Treated as necrotizing enterocolitis - No. (\%) & $09(16.0)$ \\
\hline Complications & $02(03.6)$ \\
Septicaemia - No. (\%) & $23(41.0)$ \\
Hypoglycaemic episodes - No. (\%) & $07(12.5)$ \\
Hyperglycaemic episodes - No. (\%) & $04(07.1)$ \\
Hyponatraemia - No. (\%) & \\
Thrombocytopenia - No. (\%) & \\
Catheter site related infection - No. (\%) & \\
\hline
\end{tabular}

Complications were observed among 26 (46.4\%) out of the 56 babies who received PN and several babies had more than one complication. There were no babies with evidence of cholestasis and liver injury. Catheter line was inserted and PN was started in $49(87.5 \%)$ babies on day one. Twenty $(35.7 \%)$ of them were on PN for four days. Vaminolact was used to provide amino acids, while $20 \%$ Intralipid or $20 \%$ Lipofundin was administered to supply lipid. Dextrose, potassium, calcium and sodium were administered separately as a cocktail. Other micronutrients were not included in the PN regime. All babies were fed on breast milk as the trophic feeds except one baby who was given formula milk, because of a maternal problem. Initiation of trophic feeds ranged from day one to day nine with a median of day two. On day one itself trophic feeds were started on 14 $(25 \%)$ of the babies and $51(91.0 \%)$ babies were started on trophic feeds by day three.

\section{Discussion}

The median duration of PN was 4 days in this group of neonates and trophic feeding had been started by day three in $91 \%$ babies. Early initiation of trophic feeding does not increase the risk of necrotizing enterocolitis (NEC), but promotes the maturation of the gastrointestinal tract and sustains its integrity and decreases the adverse effects associated with prolonged $\mathrm{PN}^{5}$.
Different professional bodies have laid down the indications for $\mathrm{PN}$ in neonates. $\mathrm{PN}$ is indicated when enteral feeding fails or where there is a contraindication to enteral feeding in neonates such as oesophageal atresia, intestinal atresia and risk of NEC or to uplift the growth of the premature babies $^{6,7}$. Among the many indications prematurity was the commonest to start PN according to our study.

Postnatal growth retardation is common among the very low birth weight premature infants. Proper nutrition in the early critical period of life plays an important role in growth, long-term health, neurodevelopment and in the healthy retinal development in the baby ${ }^{8,9}$. Early aggressive $\mathrm{PN}$ is beneficial and useful in reducing postnatal growth restriction especially in premature small for gestational aged neonates ${ }^{10}$. Therefore PN is lifesustaining, but early establishment of enteral feeding is always preferred to prolonged PN which is associated with many complications ${ }^{4,5}$. Hence, duration of PN should be as short as possible or at least partial enteral feeding should be started as early as possible to minimize the adverse effects and to reduce NEC and death ${ }^{11}$. There are many suggested risks associated with $\mathrm{PN}$ such as cholestasis and liver disease, venous thrombosis, metabolic changes such as hypoglycaemia and 
hyponatraemia especially in babies who are small for gestational age or preterm ${ }^{12,13}$.

The main route of administration of PN was central via the umbilical catheter according to our study, because percutaneous central catheters are expensive and are therefore not freely available locally. Due to the increased rate of complications associated with umbilical catheter use in PN administration, many neonatal units prefer to use percutaneous intravenous catheters (PIC) for $\mathrm{PN}^{14}$. Though placing PIC is potentially difficult, it has a better delivery of nutrition and is more stable than peripheral cannula and is less associated with invasive infections than peripheral cannula ${ }^{15,16}$. However, the nutritional impact of various routes on neonatal growth and long term outcome is not clear and there is limited data available. One such trial has assessed nutrient input of neonates and has found that infants who received parenteral nutrient via peripheral cannula had a statistically significant higher nutritional deficit than infants who received nutrition via a central venous catheter ${ }^{17}$.

In the Sri Lankan setup, commercial formulas in separate bags such as Vaminolact and Intralipid or Lipofundin were used to supply amino acids and energy and these formulas contain standard amounts of nutrients. A study done in a group of very low birth weight (VLBW) babies who received $\mathrm{PN}$ prescriptions with energy and high doses of amino acids were shown to promote protein synthesis more than newborns who received no lipids and standard amounts of amino acids during the first two days of life ${ }^{18}$. This finding suggests that the high amount of amino acid supply has a better outcome in the new tissue laid down among newborns. Therefore the availability of PN formulas of which the content can be adjusted is important. However, with the available formulas at the local setting we have been unable to provide adequate amino acids in a given volume without restricting the other intravenous infusions such as dextrose which may leads to hypoglycaemia in the neonate. The preparations which are usually used in the local setting lack other micronutrients such as zinc, magnesium, copper and molybdenum. Locally we use a cocktail which contains dextrose, potassium, calcium and sodium. PN should supply trace elements also other than energy and amino acids to minimize the metabolic disorders and growth impairment in the early life ${ }^{19}$. Therefore, all PN prescription should include a physiological dose of trace elements to prevent imbalances and deficiencies. Prolonged PN therapy may be associated with the development of deficiency syndromes if adequate micronutrients are not supplied from the PN formulas ${ }^{20}$. Optimization of PN therapies is necessary by outcome assessment with regards to the formula we used ${ }^{21}$. Unfortunately the outcome of locally used formulas has not been evaluated by scientific studies yet. Small sample size and the inability to eliminate the effect of confounding on the occurrence of complications related to $\mathrm{PN}$ were the major limitations of the study.

\section{Conclusions}

The median duration of PN was 4 days. Trophic feeds with expressed breast milk were started in $91 \%$ by day three. Forty six percent of babies on PN developed associated complications.

\section{Acknowledgement}

We wish to thank the mothers of the babies who were admitted to special care baby unit for their cooperation.

\section{References}

1. Moyses HE, Johnson MJ, Leaf AA, Cornelius VR. Early parenteral nutrition and growth outcomes in preterm infants: a systematic review and meta-analysis. American Journal of Clinical Nutrition 2013; 97(4):816-26.

https://doi.org/10.3945/ajen.112.042028

PMid: 23446896

2. Embleton ND, Simmer K. Practice of parenteral nutrition in VLBW and ELBW infants. World Review of Nutrition and Dietetics 2014; 110:177-89.

https://doi.org/10.1159/000358466

PMid: 24751629

3. Christmann V, Visser R, Engelkes M, de Grauw A, van Goudoever J, van Heijst A. The enigma to achieve normal postnatal growth in preterm infants - using parenteral or enteral nutrition? Acta Paediatrica 2013; 102(5):471-9.

https://doi.org/10.1111/apa.12188 PMid: 23398476

4. Calkins KL, Venick RS, Devaskar SU. Complications associated with parenteral nutrition in the neonate. Clinical Perinatology 2014; 41(2):331-45. https://doi.org/10.1016/j.clp.2014.02.006 PMid: 24873836 PMCid: PMC5384841

5. Sallakh-Niknezhad A, Bashar-Hashemi F, Satarzadeh N, Ghojazadeh M, Sahnazarli G. Early versus late trophic feeding in very low birth weight preterm infants. Iran Journal of Pediatrics 2012; 22(2): 171-6. 
PMid: 23056882 PMCid: PMC3446068

6. CSPEN guidelines for nutrition support in neonates. Asia Pacific Journal of Clinical Nutrition 2013; 22(4): 655-63.

PMid: 24231027

7. SENPE's standardization group, Consensus on paediatric enteral nutrition access: a document approved by SENPE/SEGHNP/ANECIPN/SECP. Nutricion Hospitalaria 2011; 26(1):1-15.

8. Törer B, Hanta D, Özdemir Z, Çetinkaya B, Gülcan H. An aggressive parenteral nutrition protocol improves growth in preterm infants. Turkish Journal of Pediatrics 2015; 57(3):236-41.

PMid: 26701941

9. Stoltz Sjöström E, Lundgren P, Öhlund I, Holmström G, Hellström A, Domellöf M. Low energy intake during the first 4 weeks of life increases the risk for severe retinopathy of prematurity in extremely preterm infants. Archives of Disease in Childhood Fetal and Neonatal Edition 2016; 101(2):F108-13.

https://doi.org/10.1136/archdischild-2014306816

PMid: 25678632 PMCid: PMC4789715

10. Lima AM, Goulart AL, Bortoluzzo AB, Kopelman BI. Nutritional practices and postnatal growth restriction in preterm newborns. Revista da Associacao Medica Brasileira (1992) 2015; 61(6):500-6. https://doi.org/10.1590/18069282.61.06.5 00

PMid: 26841159

11. Hamilton E, Massey C, Ross J, Taylor S. Early enteral feeding in very low birth weight infants. Early Human Development 2014; 90(5):227-30.

https://doi.org/10.1016/j.earlhumdev.2014 .02 .005

PMid: 24612934

12. Orso G, Mandato C, Veropalumbo $C$, Cecchi N, Garzi A, Vajro P. Pediatric parenteral nutrition-associated liver disease and cholestasis: Novel advances in pathomechanisms-based prevention and treatment. Digestive and Liver Disease 2016; 48(3):215-22.

https://doi.org/10.1016/j.dld.2015.11.003

PMid: 26698410
13. Lee SM, Namgung R, Park MS, Eun HS, Kim NH, Park KI, et al. Parenteral nutrition associated cholestasis is earlier, more prolonged and severe in small for gestational age compared with appropriate for gestational age very low birth weight infants. Yonsei Medical Journal 2013; 54(4): $839-44$.

https://doi.org/10.3349/ymj.2013.54.4.839 PMid: 23709416 PMCid: PMC3663238

14. Montaruli E, Pfister RE, Wildhaber BE. Sterile hepatic abscess secondary to administration of parenteral fluids via an umbilical venous catheter in a premature baby. Journal of Pediatric Gastroenterology and Nutrition 2011; 53(5): 575-6.

https://doi.org/10.1097/MPG.0b013e3182 $1 \mathrm{c} 5 \mathrm{acf}$

PMid: 22020540

15. Ainsworth SB, McGuire W. Percutaneous central venous catheters versus peripheral cannulae for delivery of parenteral nutrition in neonates. Journal of the American Medical Association 2016; 315(23): 2612-3.

https://doi.org/10.1001/jama.2016.7020

PMid: 27327804

16. Danski MT, Mingorance P, Johann DA, Vayego SA, Lind J. Incidence of local complications and risk factors associated with peripheral intravenous catheter in neonates. Revista da Escola de Enfermagem USP 2016; 50(1): 22-8. https://doi.org/10.1590/S00806234201600 00100003

PMid: 27007416

17. Ainsworth SB, Furness J, Fenton AC. Randomized comparative trial between percutaneous long lines and peripheral cannulae in the delivery of neonatal parenteral nutrition. Acta Paediatrica 2001; 20:1016-20.

18. Vlaardingerbroek H, Schierbeek H, Rook D, Vermeulen MJ, Dorst K, Vermes A, et al., Albumin synthesis in very low birth weight infants is enhanced by early parenteral lipid and high-dose amino acid administration. Clinical Nutrition 2016; 35(2):344-50.

https://doi.org/10.1016/j.clnu.2015.04.019 PMid: 26028361 
19. Rigo J, Senterre T. Intrauterine-like growth rates can be achieved with premixed parenteral nutrition solution in preterm infants. Journal of Nutrition 2013; 143(12 Suppl):2066S-2070S. https://doi.org/10.3945/jn.113.177006 PMid: 24108133

20. Stehle P, Stoffel-Wagner B, Kuhn KS. Parenteral trace element provision: recent clinical research and practical conclusions.
European Journal of Clinical Nutrition 2016; 70(8):886-93.

https://doi.org/10.1038/ejen.2016.53

PMid: 27049031 PMCid: PMC5399133

21. Kamarudin NA, Manan MM, Zulkifly $\mathrm{HH}$, Neoh CF, Ali SM, Ming LC. Amino acid dosing in parenteral nutrition for very low birth weight preterm neonates: an outcome assessment. Asia Pacific Journal of Clinical Nutrition 2016; 25(1):53-61. PMid: 26965762 